\title{
Survey of Historical Nesting Territories and Potential High-quality Habitat for Northern Goshawks on the Kootenai National Forest
}

\author{
Prepared for: \\ USDA Forest Service \\ Kootenai National Forest \\ Prepared by: \\ Coburn Currier \\ Montana Natural Heritage Program \\ a cooperative program of the \\ Montana State Library and the University of Montana
}

September 2007

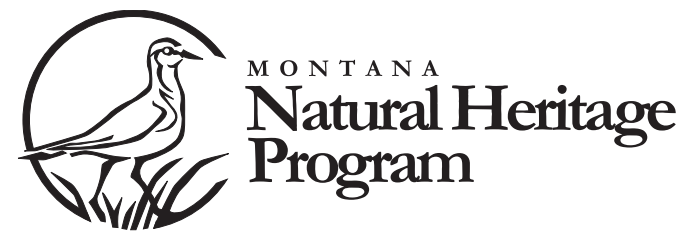





\title{
Survey of Historical Nesting Territories and Potential High-quality Habitat for Northern Goshawks on the Kootenai National Forest
}

\author{
Prepared for: \\ USDA Forest Service \\ Kootenai National Forest \\ 1101 U.S. Hwy 2 West \\ Libby, MT 59923
}

Agreement Number:

04-CS-11011400-041

Prepared by:

Coburn Currier

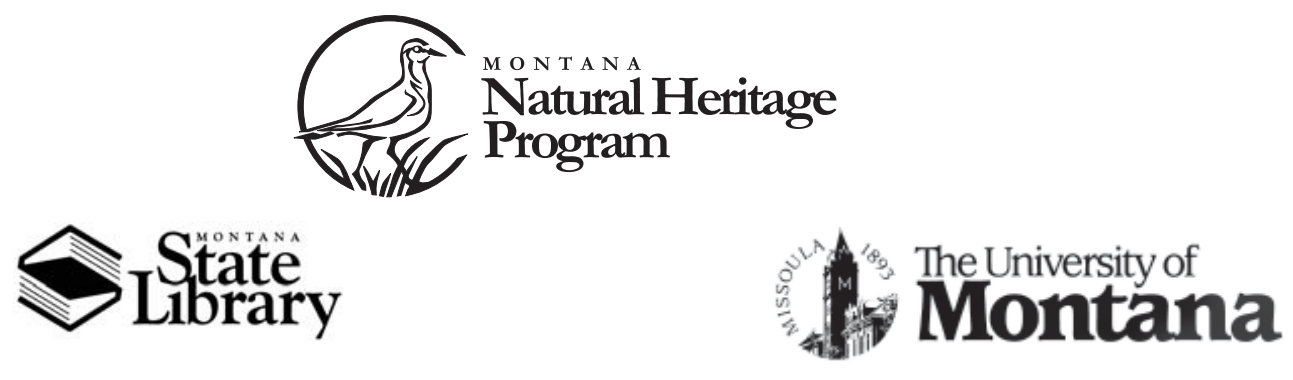

(C) 2007 Montana Natural Heritage Program

P.O. Box 201800 • 1515 East Sixth Avenue • Helena, MT 59620-1800 • 406-444-5354 
This document should be cited as follows:

Currier, C. 2007. Survey of Historical Nesting Territories and Potential High-quality Habitat for Northern Goshawks on the Kootenai National Forest. Report to the USDA Forest Service, Kootenai National Forest. Montana Natural Heritage Program, Helena, Montana. 15 pp. 


\section{Executive Summary}

In 2005, the Montana Natural Heritage Program began surveying Northern Goshawk historical nesting territories on the Kootenai National Forest with the overall objective of gaining a clearer understanding of breeding goshawk populations and habitat association in order to better assist management and conservation of the species on the Forest. Surveying historical territories was the first priority in a multi-year project directed at eventually having Forest-wide systematic surveys of Northern Goshawk occurrence and habitat use. The second priority was to survey potential highquality nesting habitat as identified by predictive models of old-growth habitat across the Forest.

Seventeen historical territories and five potential high-quality habitat sites were surveyed on the Kootenai National Forest in three successive field seasons (2005-2007). This effort encompassed a total of 369 call stations covering approximately 6445 acres (10.07 square miles).

Of the 17 historical territories surveyed, one territory was found to still be active. This territory, in Haines Gulch (Cabinet District), should be surveyed again in order to document nesting and determine reproductive success. Also, an auditory response to taped playback was made by an adult flying south over the East Fork Pipe Creek valley in the Purcell historical territory. A detailed followup search was completed with no nest found and no additional observations made. Further survey work in the vicinity may yield a new nest location.

Of the 5 potential high-quality habitat parcels surveyed, a single visual-only response was made by an adult in the Beetle Creek area of Pete Creek drainage. This bird flew into the call station after taped playback and then flew out of the station area. An exhaustive search was made of the immediate vicinity for any evidence of nesting. However, no other observations were made and no additional responses to taped playback occurred. Further survey work in the Beetle Creek area may yield a new nesting location.

Priorities for the future include: (1) continue surveying areas identified as having high-quality nesting habitat by predictive models; and (2) perform follow-up surveys in the vicinity of the positive responses in an effort to document continued nesting in those areas. 


\section{ACKNOWLEDGEMENTS}

I would like to thank Wayne Johnson, Wildlife Biologist, of the Kootenai National Forest Supervisor's Office for financial support and assistance with survey protocol preparation and planning. I would also like to thank Kootenai Forest Biologists Gunter Heinz, Lynn Johnson, Annie Dueker, Al Bratkovitch, Jenny Holifield, and Glen Gill for their valuable input regarding historical territories, with a special thank you to Glen for taking time from his busy schedule to survey goshawks in the Yaak with me. Thanks also to Susan Lenard and Scott Blum of the Montana Natural Heritage Program (MTNHP) for assistance in the field, Paul Hendricks (MTNHP) for input on survey design and Bryce Maxell (MTNHP) for his review and editing of this report. 


\section{Table of Contents}

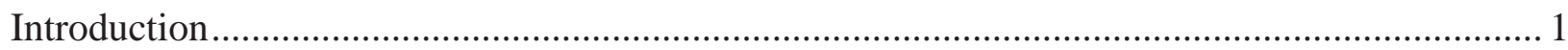

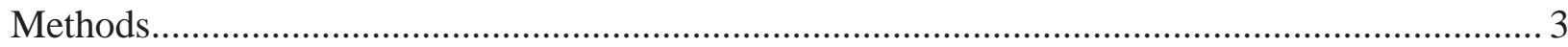

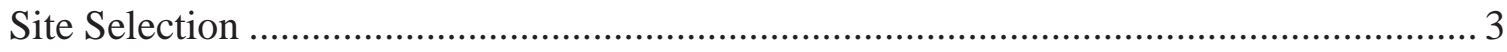

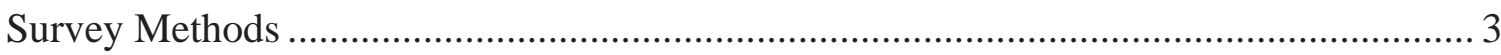

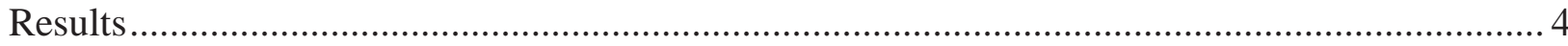

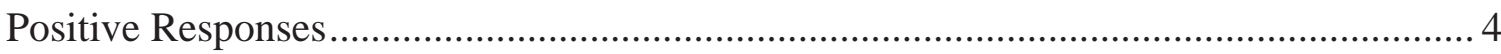

Historical Territories Surveyed ......................................................................................... 5

Historical Territories Determined Unnecessary to Survey ……………………………..... 10

High-quality Potential Nesting Habitat Parcels .................................................................. 10

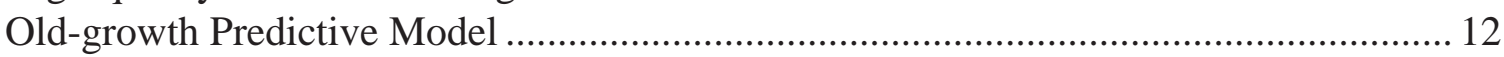

Suggestions for Future ................................................................................................. 14

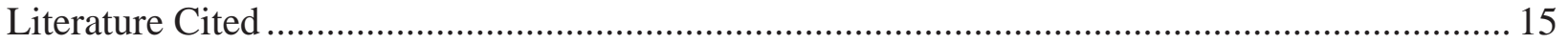

Appendix A: Global/State Rank Definitions

List OF Figures

Figure 1. Northern Goshawk Observations in Montana ............................................................. 1

Figure 2. Status of Township-Range-Section-scale Northern Goshawk historical nesting territory surveys on the Kootenai National Forest after 2006 field season .................. 4

Figure 3. Status of potential high-quality Northern Goshawk nesting habitat parcels on the Kootenai National Forest after the 2007 field season .............................................. 5

Figure 4. Location of call stations in Haines Gulch historical territory ......................................... 6

Figure 5. Location of call stations in Edna Creek historical territory ............................................ 6

Figure 6. Location of call stations in Lower Edna historical territory ............................................ 6

Figure 7. Location of call stations in Sink Creek historical territory............................................ 7

Figure 8. Location of call stations in Weasel Cabin historical territory......................................... 7

Figure 9. Location of call stations in Bear Creek historical territory .......................................... 7

Figure 10. Location of call stations in Davis Mtn. and Weigel historical territories ...................... 7

Figure 11. Location of call stations in LaFoe historical territory ……............................................ 8

Figure 12. Location of call stations in Little Cherry historical territory .......................................... 8

Figure 13. Location of call stations in McMillan historical territory................................................ 8

Figure 14. Location of call stations in Purcell historical territory ................................................. 9

Figure 15. Location of call stations in Slick Gulch historical territory......................................... 9

Figure 16. Location of call stations in Upper Sutton Gulch historical territory ............................ 9

Figure 17. Location of call stations in Basin Creek historical territory ........................................... 9

Figure 18. Location of call stations in Unnamed \#1 (Stimson) historical territory ...................... 10

Figure 19. Location of call stations in Unnamed \#2 (Lost Horse Mtn.) historical territory ....... 10

Figure 20. Location of call stations in Beetle Creek potential high-quality habitat parcel.......... 11

Figure 21. Location of call stations in Boyd Hill potential nesting area ...................................... 11

Figure 22. Location of call stations in Cougar Ridge potential high-quality habitat parcel ........ 11

Figure 23. Location of call stations in Kookoo Creek potential high-quality habitat parcel...... 12

Figure 24. Location of call stations in O'Brien Creek potential high-quality habitat parcel...... 12

Figure 25. Breeding and non-breeding Northern Goshawk observations on the Kootenai

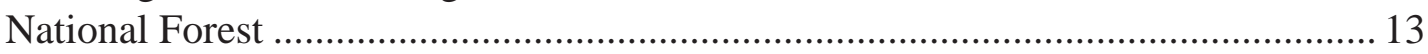





\section{INTRODUCTION}

The Northern Goshawk (Accipiter gentilis), a large forest raptor, breeds in temperate habitats throughout the American West (Squires and Reynolds 1997). The species is listed as "Sensitive" by Region 1 of the U.S. Forest Service, as well as an Animal Species of Concern (G5, S3) (see Appendix A for definitions) by the Montana Natural Heritage Program and Montana Fish, Wildlife \& Parks (Montana Natural Heritage Program 2006). In Montana, this species occurs most often in mature to late successional conifer forests of the Columbian Highlands (northwestern Montana) and Rocky Mountain Forest (westcentral Montana and east of the Continental Divide) (Hayward and Escano 1989). The species has been confirmed breeding in 27 of 49 Latilongs in the state (Lenard et al. 2003), with most observations in the western and central mountain regions (Figure 1).
Northern Goshawks are year-round residents in Montana. However, in-state seasonal movements do occur, usually between wintering and nesting locations. Pair formation typically begins in late March to early April in mountainous areas of the west (Beebe 1974; McGowan 1975; Reynolds and Wight 1978) and incubation is initiated by late April to early May (Reynolds and Wight 1978; Henny et al. 1985). Phenology is determined by elevation and food availability.

As of spring 2005, the Kootenai National Forest identified 20 Northern Goshawk nesting territories with a current status of unknown (not checked in past 3 years) or lost (nest tree or stand impacted and site abandoned). The last survey dates of most of the territories extended back to the 1980's with one territory dating to 1978 . Due to the lack of breeding records on the Forest and the amount

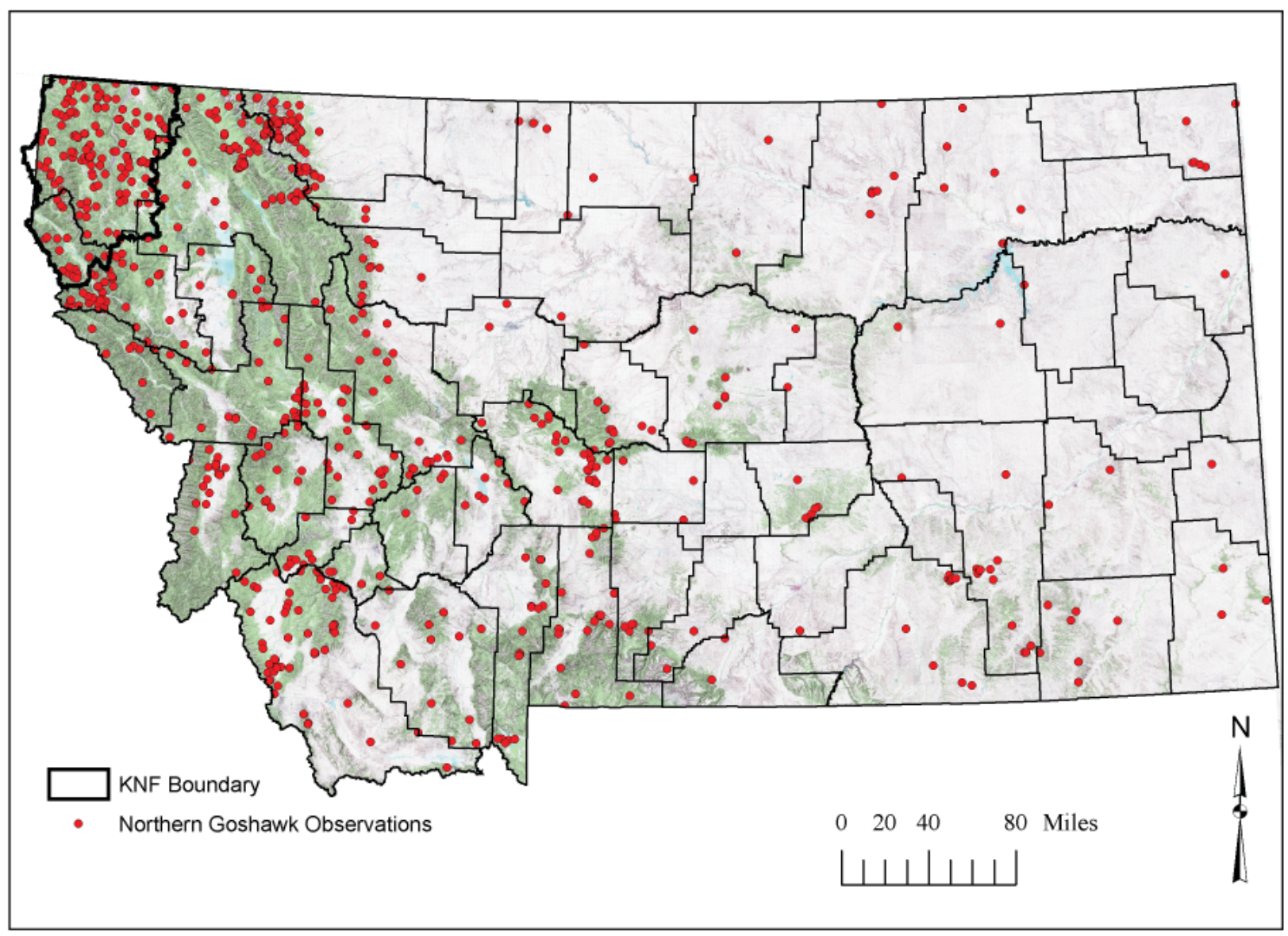

Figure 1. Northern Goshawk Observations in Montana 
of time elapsed since historical breeding areas were surveyed, the Forest initiated a multi-year project to systematically document occurrence and habitat use of Northern Goshawks in order to assist management and conservation of the species. Specific objectives included: (1) development of a survey strategy and protocol; (2) conducting presence and nesting pair surveys in historical nesting territories not checked in the last three years; and (3) conducting surveys of high-quality potential nesting habitat parcels determined by old-growth habitat predictive models where prior surveys had not been conducted. 


\section{Methods}

\section{Site Selection}

\section{Historical Territories}

The Kootenai National Forest provided a spreadsheet of historical Northern Goshawk territories including Township-Range-Section (TRS) information for each of 20 (17 statusunknown and 3 status-lost) historical territories not surveyed in the past three years. These 20 locations were the top priority for survey work.

\section{Potential High-quality Habitat}

The Forest provided a GIS coverage of predicted old-growth habitat. These predictive models categorized forest "patches" into several types. Those of importance are effective oldgrowth-designated (DEFF), effective oldgrowth-undesignated (UEFF), replacement stand-designated (DREP) and replacement stand-undesignated (UREP). TRS locations were selected within the Forest where a significant portion of the section contained DEFF and UEFF habitat types. These potential high-quality habitat parcels were the second priority for survey work.

\section{Survey Methods}

Spring presence and nesting surveys were conducted during May and June when goshawks defend territories, build nests, and incubate eggs.

Transects were established within each historical nesting territory with parallel transects located approximately 250 meters apart. Whenever possible, road access was used as a transect for ease of travel within the territory. Calling stations were placed every 250-300 meters along each transect within each historical territory. Taped Northern Goshawk vocalizations were broadcast three times at each station at compass bearings of 60,180 , and 300 degrees. Each broadcast was followed by 30 seconds of silence while listening for a response. This process was repeated three times at each station and was continued at all stations along all transects in the historical territory until all suitable forested habitat in the territory was surveyed or until a response was detected.

When a goshawk responded to the taped vocalization, a detailed search was initiated for the bird(s) and/or nest in the direction of the response. Protocols called for collection of information on the nest stand and tree, if a nest was located, including territory data (nest ID, TRS, latitude/ longitude location of tree, name, and status), stand data (crown closure, elevation, forest type, major species, aspect and slope percent) and tree data (tree species, dbh, height of tree and height to nest), as well as any other comments related to the nest location.

For any active territories found during the spring surveys, protocols called for a second visit to the nest location during the fledgling stage in early to mid-July. This visit would determine nest success, defined as the production of at least one fledgling from the nest. However, no active nests were located during field work and therefore summer surveys were not conducted. 


\section{Results}

A total of 17 historical nesting territories were surveyed during the 2005 and 2006 field seasons. Three additional territories were determined not worthy of survey after consultation with area biologists and review of aerial photography indicating heavy timber harvest and virtually no suitable forested habitat present (Figure 2). In addition, five potential high-quality habitat parcels were surveyed during the 2006 and 2007 field seasons (Figure 3). In total, 369 call stations were surveyed covering approximately 6445 acres or 10.07 square miles of forested habitat within the Kootenai National Forest.

\section{Positive Responses}

A single response to taped playback occurred in the Purcell historical territory on 26 May 2005 with a vocal response made by an adult. This individual was subsequently observed flying south over the East Fork Pipe Creek valley. A detailed search was completed with no nest found and no further observations made. Presence of an adult indicates a possible nesting pair somewhere in the East Fork Pipe Creek valley. Further survey work in the vicinity may yield a new nest location.

A single response to taped playback occurred in the Haines Gulch historical territory on 5 July 2006 with a vocal response made by an adult. This individual was subsequently observed flying northeast over Haines Gulch. Progress up the drainage (toward the initial response) became hazardous and eventually impassable. However, repeated taped playback resulted in repeated vocal

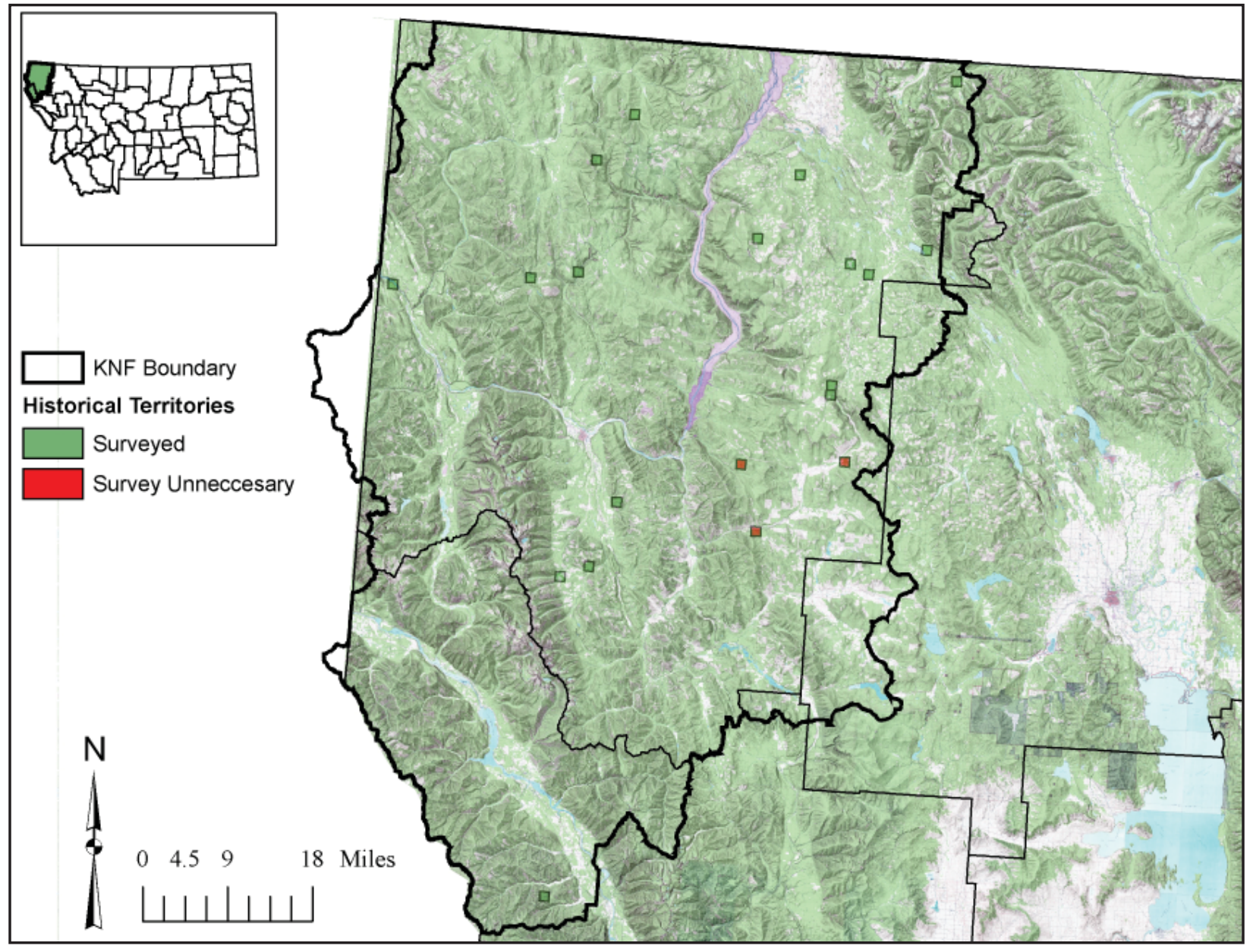

Figure 2. Status of Township-Range-Section-scale Northern Goshawk historical nesting territory surveys on the Kootenai National Forest after the 2006 field season. 


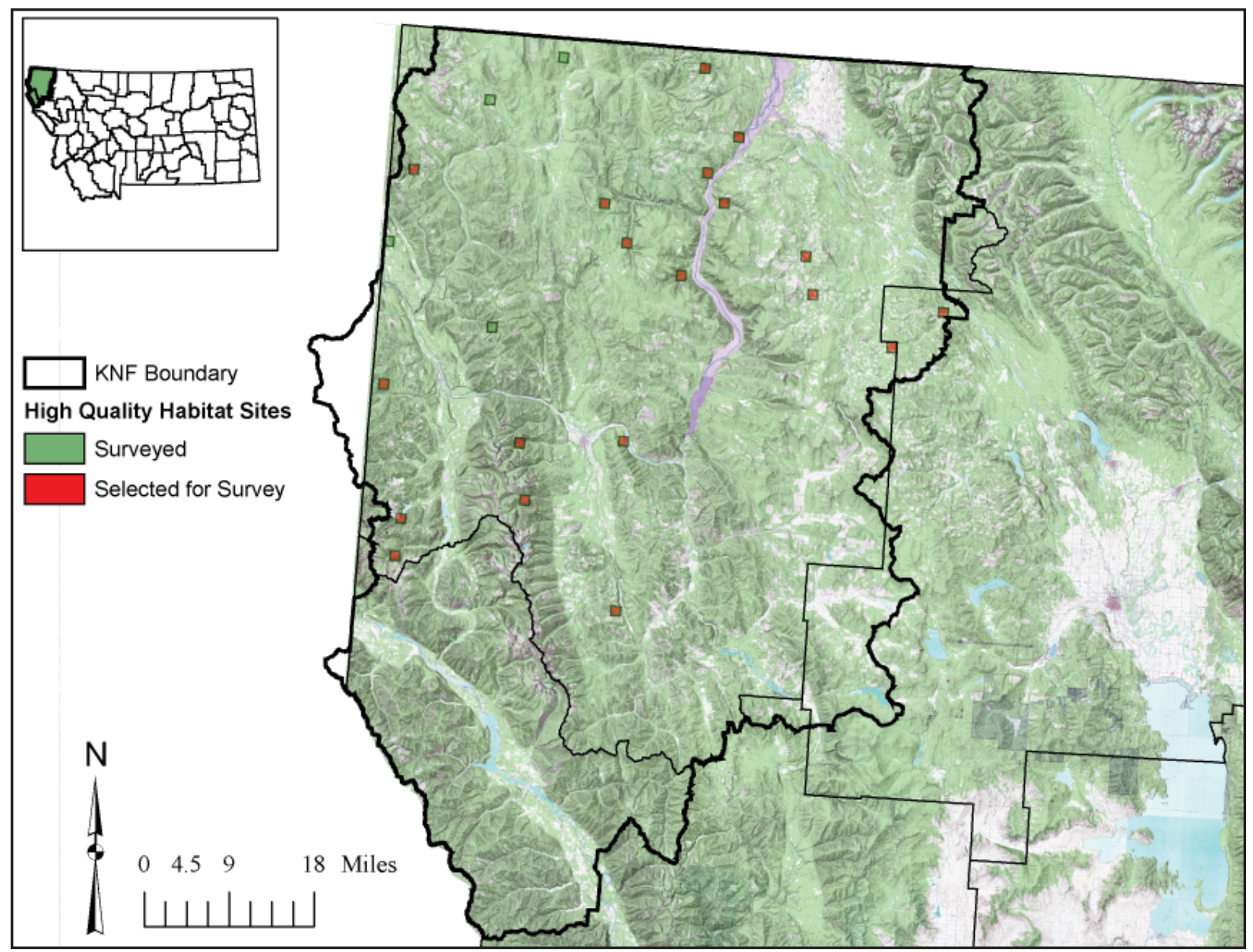

Figure 3. Status of potential high-quality Northern Goshawk nesting habitat parcels on the Kootenai National Forest after the 2007 field season.

response to the northeast. A detailed search of the vicinity was conducted. In the end, no nest was found and incoming inclement weather ended the search effort. Presence of a territorial adult indicates a probable nesting pair somewhere in upper Haines Gulch.

A visual investigation to taped playback occurred in the Beetle Creek potential high-quality habitat parcel on 26 June 2007 and a visual identification was made of an adult. This individual was observed flying into the call station area from the east where it subsequently landed in a tree. After landing, it soon flew to the north and was lost to sight. A detailed search for the bird, a nest, or whitewash on the bases of trees was undertaken in the area. Subsequent abbreviated calls were made to the east, south, and north of the call station as well. However, no further visual contacts were made. This bird never made any vocal responses to taped playback or to the presence of observers. Even so, presence of an adult indicates a possible nesting pair somewhere in the Beetle Creek/Pete Creek area. Further survey work in the vicinity may yield a new nest location.

\section{Historical Territories Surveyed}

Of the 20 documented historical territories on the Kootenai National Forest, the following 17 sections were surveyed for Northern Goshawk presence in 2005 and 2006. Many areas were recently harvested for timber and surveys were restricted to suitable forested habitat within the identified section. The old-growth predictive model was used to assist with the prioritization of search areas within the territory. One, four, seven, two, and three historical territories were surveyed in the Cabinet, Fortine, Libby, Rexford, and Three Rivers Districts, respectively. 


\section{Cabinet District}

\section{Haines Gulch - 22N 31W sec. 10}

On 5 July 2006, 11 stations, covering

approximately 193 acres of forested habitat

containing the historical nesting territory, were surveyed using taped playback (Figure 4).

During the 11th call station within the area of the historical territory a response was made by an adult Northern Goshawk at 12:35 pm. The adult was observed approaching the call station to investigate and subsequently flew past the call station and continued over Haines Gulch to the northeast. The exact location of the call station was: (NAD 27) Zone 11: Easting - 607956 Northing - 5281052 (Locational Accuracy 25.0 meters) in the SW corner of T22NR31W sec.10. Reproductive status and gender were not possible to determine. A detailed search to the southwest (direction from which bird was flying) was initially undertaken, but terrain became hazardous and eventually impassable. The bird was still vocalizing with the "kek-kek" call to the northeast. After returning to the call station, a search was conducted down the drainage toward the location of the bird. Two more taped playbacks were made with vocal response by the bird each time. A third taped playback did not elicit any response. An exhaustive search of the forest failed to locate a nest and no subsequent visual or auditory observations were made. By 16:30 inclement weather halted the search for the bird. An adult goshawk responding aggressively to taped playback during the breeding season indicates a probable nesting pair somewhere in the upper Haines Gulch area. Further survey work in the vicinity may yield the nest location.

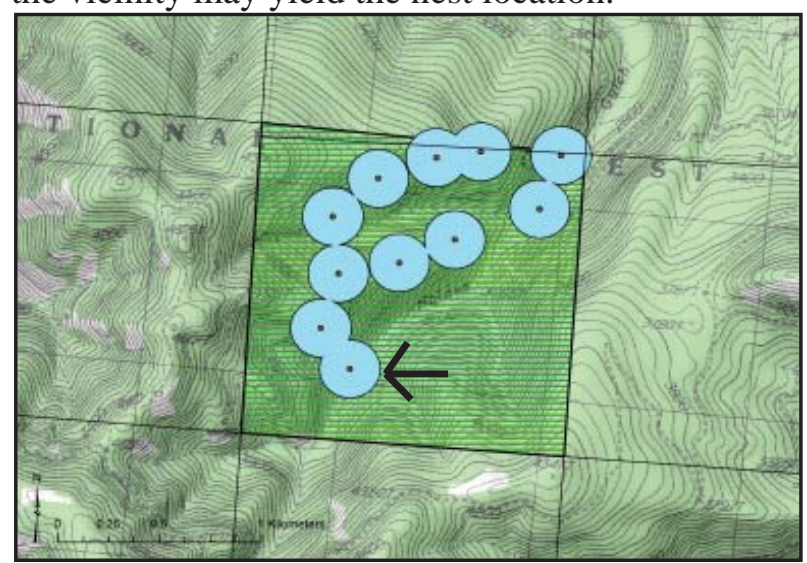

Figure 4. Location of call stations in Haines Gulch historical territory. Location of 2006 positive response at 11th station indicated by arrow.

\section{Fortine District}

Edna Creek - 34N 26W sec. 28

On 29 May 2005, 12 stations, covering approximately 210 acres of forested habitat containing the historical nesting territory, were surveyed using taped playback (Figure 5). The territory was reported in the SE corner of the section. The NE corner of the section and the northern portion were private land. No responses were detected.

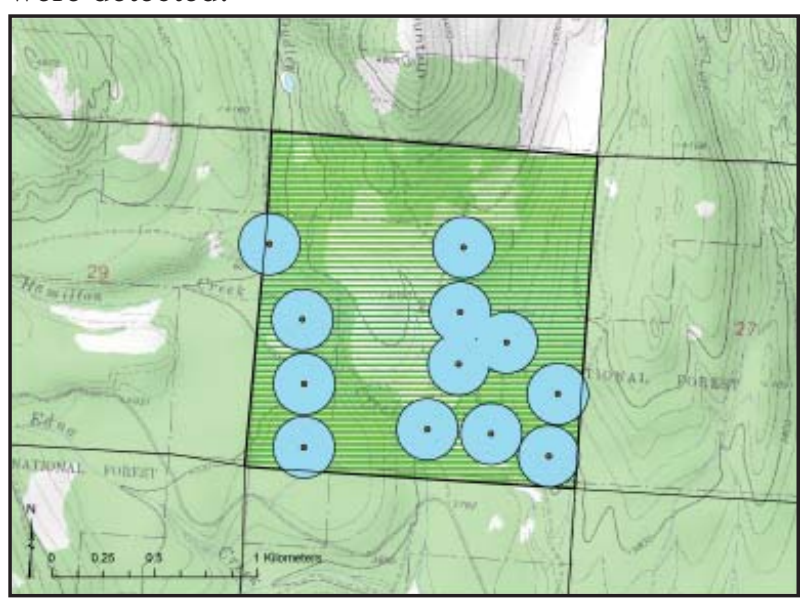

Figure 5. Location of call stations in Edna Creek historical territory.

\section{Lower Edna - 34N 26W sec. 35}

On 29 May 2005, 14 stations, covering approximately 245 acres of forested habitat containing the historical nesting territory, were surveyed using taped playback (Figure 6). The territory was reported in the SW corner of the section. The NW and SE corners and the northern portion of the section were private land. No responses were detected.

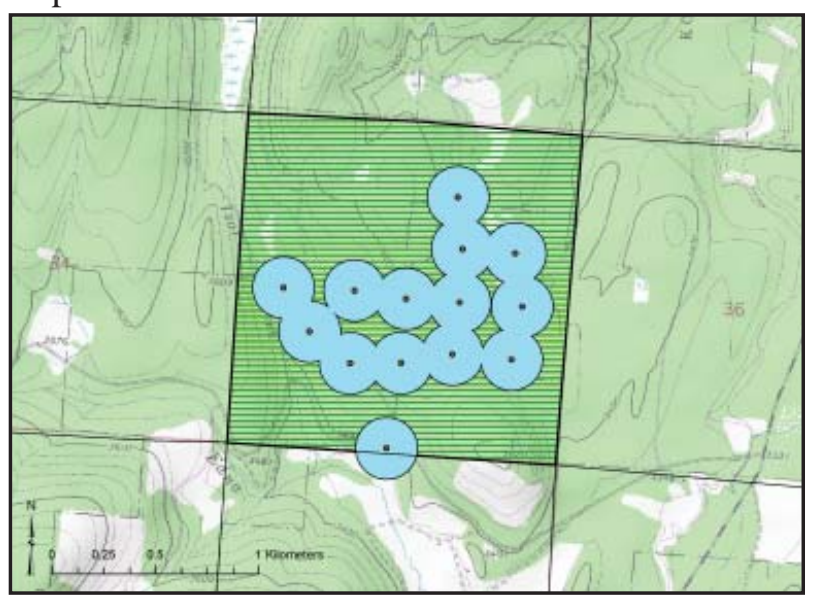

Figure 6. Location of call stations in Lower Edna historical territory. 
Sink Creek - 34N 25W sec. 14

On 28 May 2005, 11 stations, covering approximately 193 acres of forested habitat containing the historical nesting territory, were surveyed using taped playback (Figure 7). The territory was reported in the NE corner of the section (area had been harvested and no survey was necessary). No responses were detected.

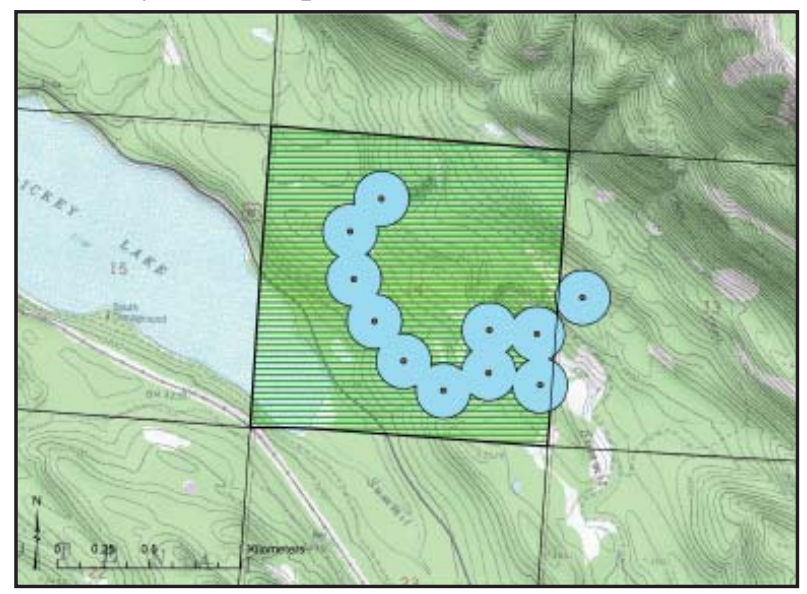

Figure 7. Location of call stations in Sink Creek historical territory.

\section{Weasel Cabin - 37N 24W sec. 17}

On 30 May 2005, 18 stations, covering approximately 315 acres of forested habitat containing the historical nesting territory, were surveyed using taped playback (Figure 8). The territory was reported in the NE corner of the section. No responses were detected.

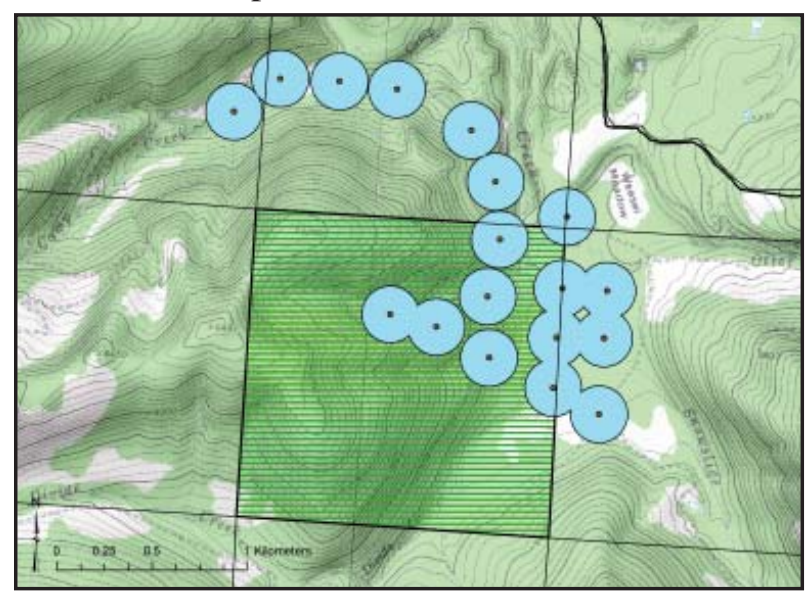

Figure 8. Location of call stations in Weasel Cabin historical territory.

\section{Libby District}

\section{Bear Creek - 28N 30W sec. 18}

On 20 May and 27 May 2005, 28 call stations, covering approximately 489 acres of forested habitat containing the historical nesting territory, were surveyed using taped playback (Figure 9). No responses were detected.

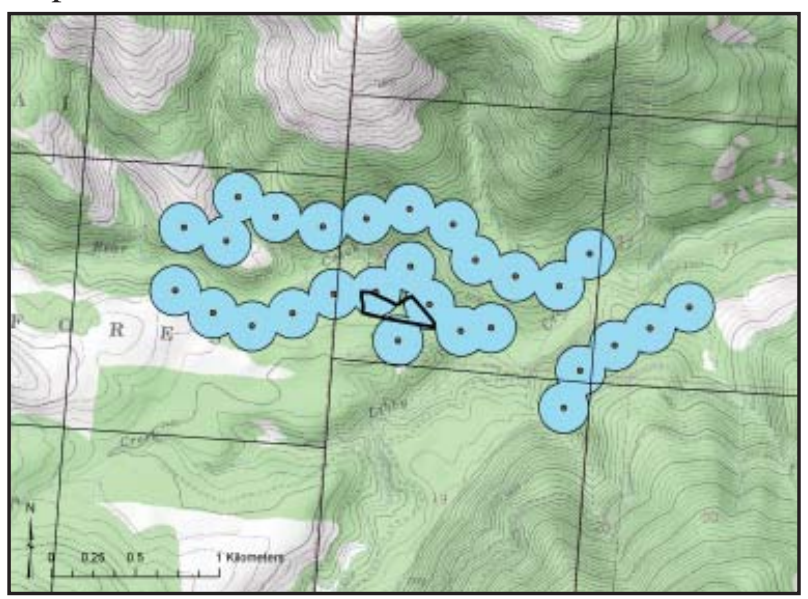

Figure 9. Location of call stations in Bear Creek historical territory. Historical nest reported in forest stand indicated in black.

Davis Mountain - 32N 27W sec. 36

\section{Weigel - 31N 27W sec. 1}

On 7 July 2005, 24 stations, covering approximately 420 acres of forested habitat containing the historical nesting territories, were surveyed using taped playback (Figure 10). No responses were detected.

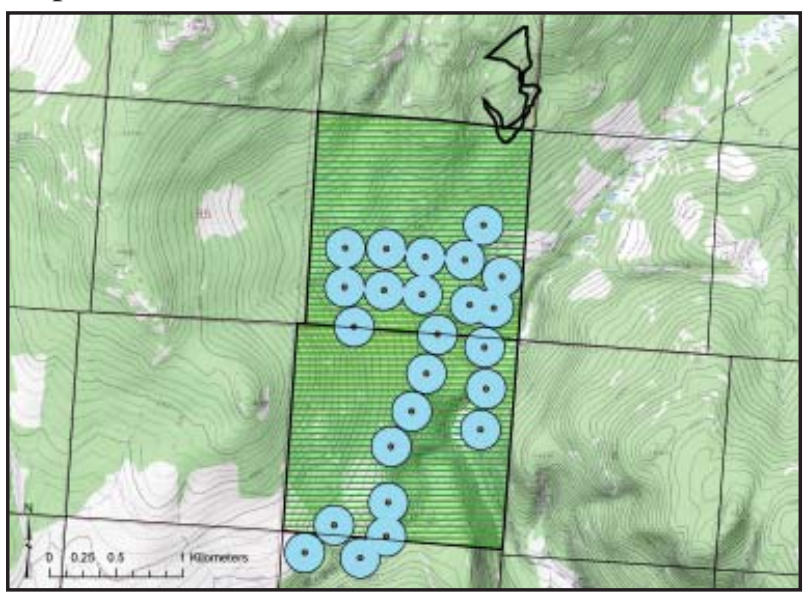

Figure 10. Location of call stations in Davis Mtn. historical territory (upper) and Weigel historical territory (lower). Historical Davis Mtn. territory reported in forest stand indicated in black (area had been harvested, no survey done). 
LaFoe - 33N 32W sec. 13

On 21 May 2005, 21 stations, covering approximately 367 acres of forested habitat containing the historical nesting territory, were surveyed using taped playback (Figure 11). No responses were detected.

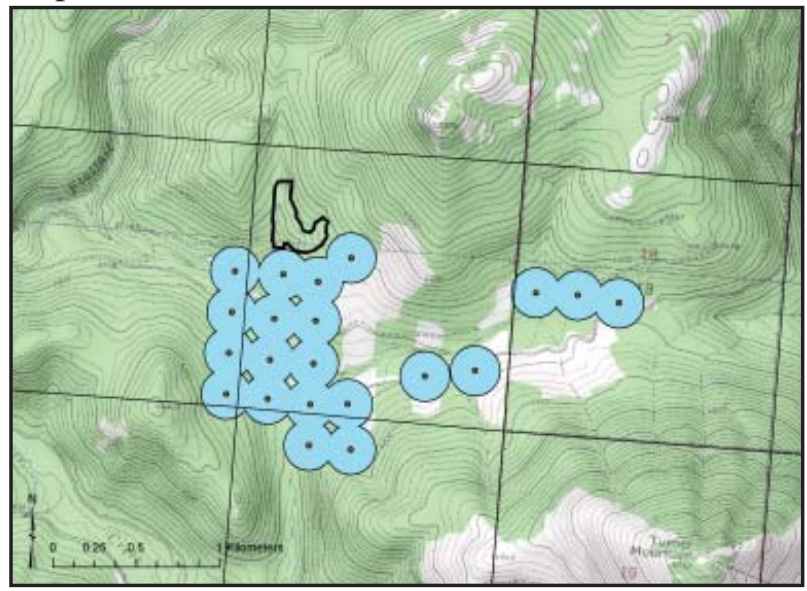

Figure 11. Location of call stations in LaFoe historical territory. Historical nest reported in forest stand indicated in black (stand and area to north had been harvested, no survey done).

\section{Little Cherry - 28N 31W sec. 22}

On 18 May 2005, 19 call stations, covering approximately 332 acres of forested habitat containing the historical nesting territory, were surveyed using taped playback (Figure 12). No responses were detected.

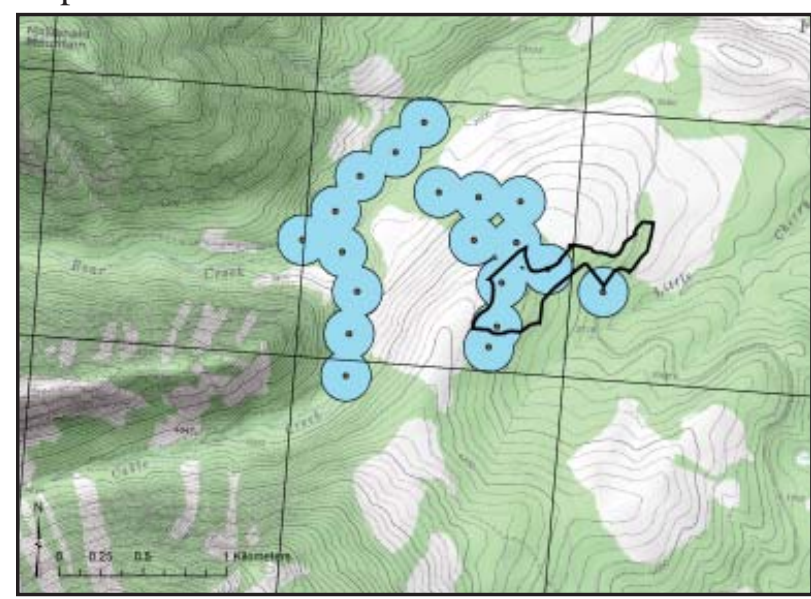

Figure 12. Location of call stations in Little Cherry historical territory. Historical nest reported in forest stand indicated in black.

\section{McMillan - 29N 30W sec. 8}

On 19 May 2005, 21 call stations, covering approximately 367 acres of forested habitat containing the historical nesting territory, were surveyed using taped playback (Figure 13). No responses were detected.

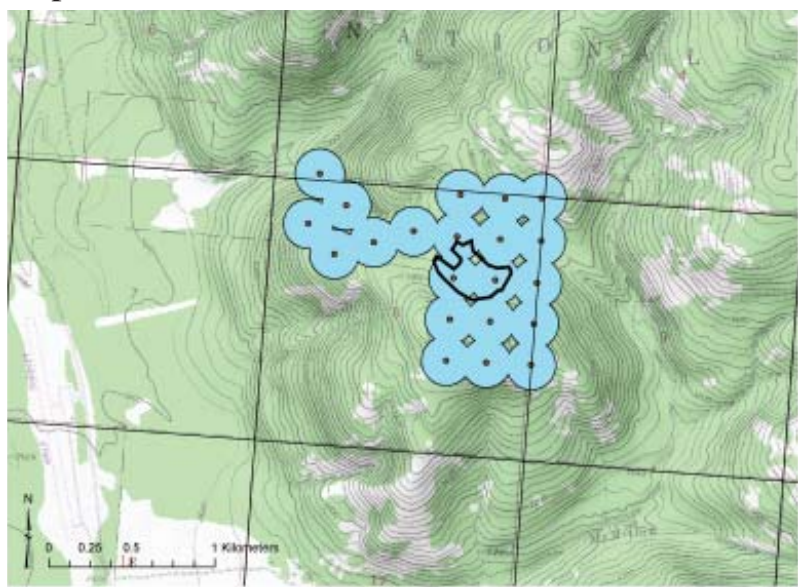

Figure 13. Location of call stations in McMillan historical territory. Historical nest reported in forest stand indicated in black.

\section{Purcell - 33N 31W sec. 10}

On 26 May 2005, 18 stations, covering approximately 315 acres of forested habitat containing the historical nesting territory, were surveyed using taped playback (Figure 14). During the 7th call station within the area of the historical territory a response was made by an adult Northern Goshawk at 12:14 pm. This adult was observed approaching the call station to investigate and subsequently flew past the call station out over the East Fork Pipe Creek valley. The exact location of the call station was: (NAD 27) Zone 11: Easting 604504 Northing - 5387221 (Locational Accuracy 9.2 meters) in the SE corner of T33NR31W sec.10. Reproductive status and gender were not possible to determine. A detailed search to the north (direction from which bird was flying) was undertaken, including further taped playback, with no nest found and no subsequent visual or auditory observations made. An adult goshawk weakly responding to taped "kek-kek" calls during the breeding season indicates a possible nesting pair somewhere in the East Fork Pipe Creek valley. Further survey work in the vicinity may yield a new nest location. 


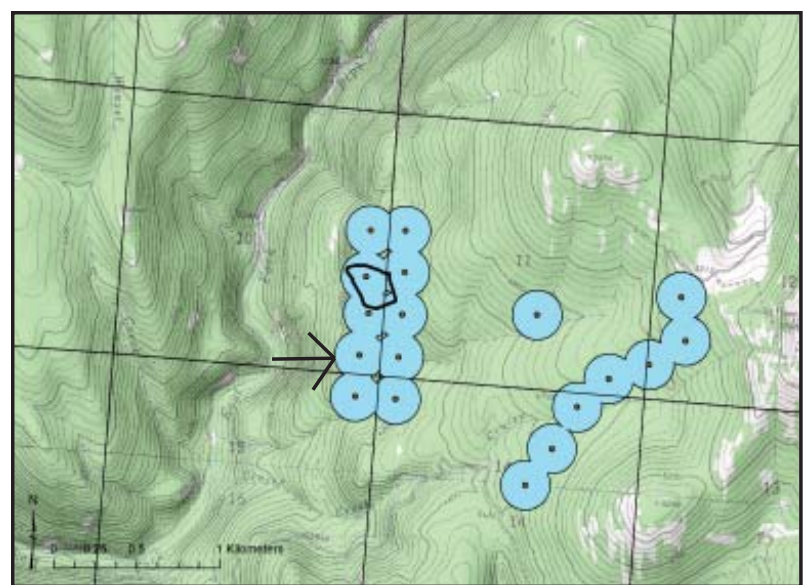

Figure 14. Location of call stations in Purcell historical territory. Historical nest reported in forest stand indicated in black. Location of 2005 positive response at 7th station indicated by arrow.

\section{Rexford District}

\section{Slick Gulch - 35N 27W sec. 9}

On 1 July 2005, 18 stations, covering approximately 315 acres of forested habitat containing the historical nesting territory, were surveyed using taped playback (Figure 15). The area to the north of the surveyed section was private land. No responses were detected.

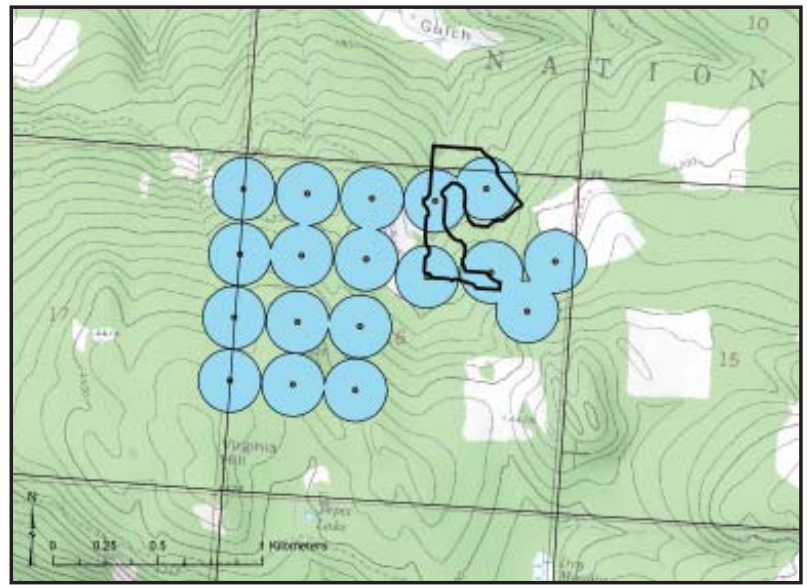

Figure 15. Location of call stations in Slick Gulch historical territory. Historical territory reported in forest stand indicated in black.

\section{Upper Sutton - 34N 28W sec. 14}

On 6 July 2005, 19 stations, covering approximately 332 acres of forested habitat containing the historical nesting territory, were surveyed using taped playback (Figure 16). No responses were detected.

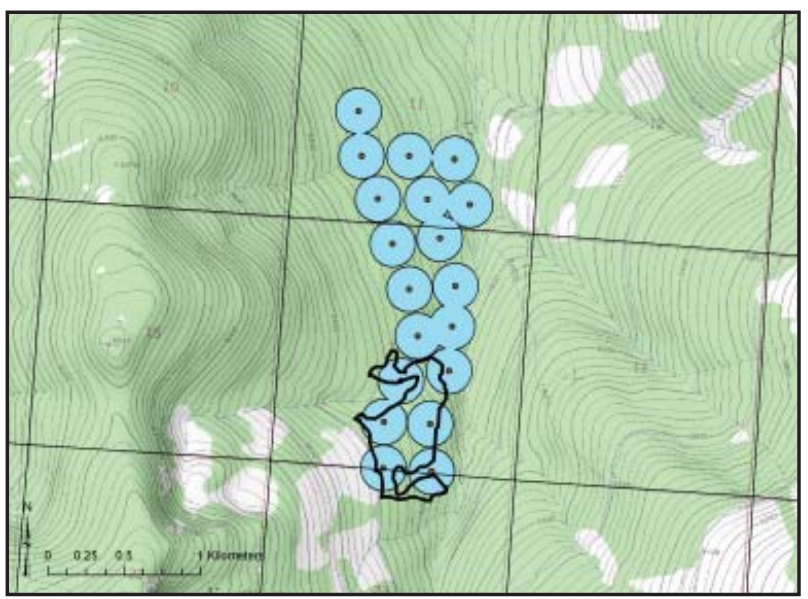

Figure 16. Location of call stations in Upper Sutton historical territory. Historical territory reported in forest stand indicated in black.

\section{Three Rivers District}

\section{Basin Creek - 35N 31W sec. 11}

On 29 May 2005, 14 stations, covering approximately 245 acres of forested habitat containing the historical nesting territory, were surveyed using taped playback (Figure 17). No responses were detected.

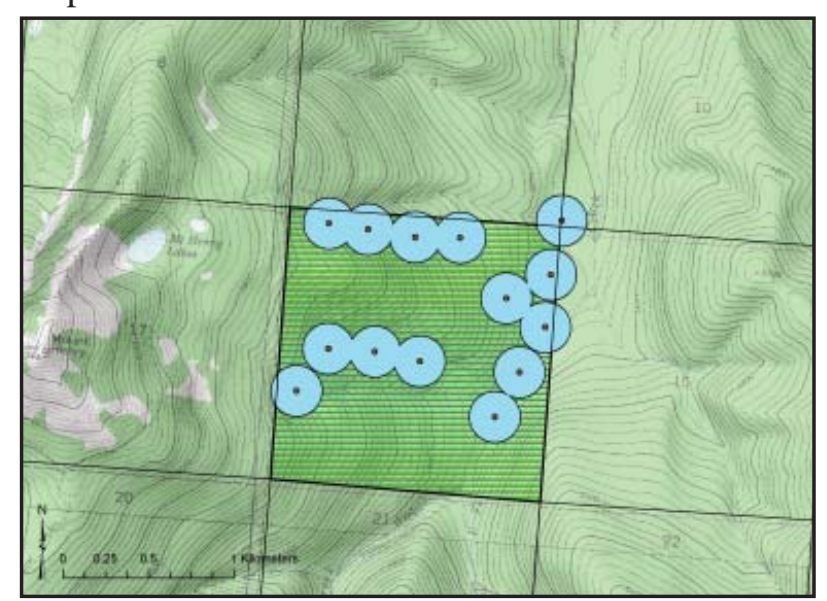

Figure 17. Location of call stations in Basin Creek historical territory. 
Unnamed \#1 (Stimson) - 33N 34W sec. 28

On 28 May 2005, 11 stations, covering approximately 193 acres of forested habitat containing the historical nesting territory, were surveyed using taped playback (Figure 18). No responses were detected.

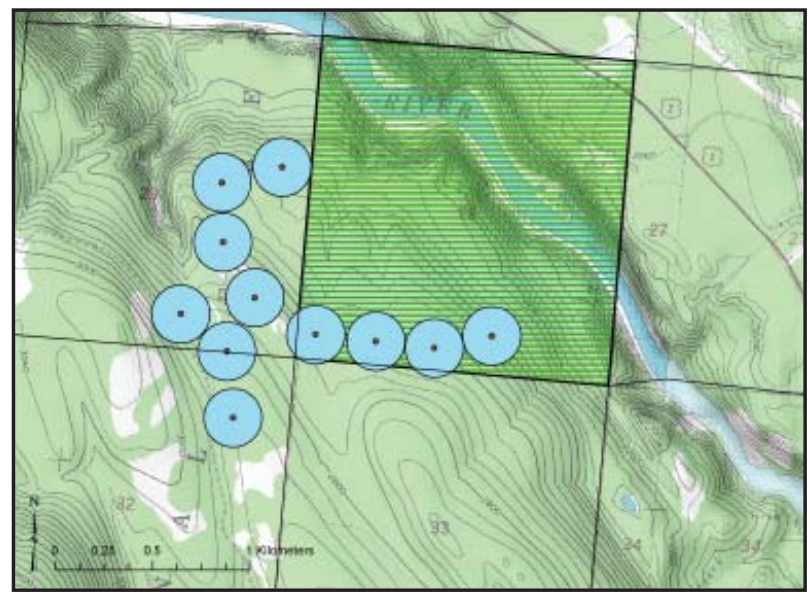

Figure 18. Location of call stations in Unnamed \#1 (Stimson) historical territory. Majority of historical territory was harvested and no survey was necessary.

\section{Unnamed \#2 (Lost Horse Mountain) - 35N} $31 \mathrm{~W}$ sec. 11

On 3 July 2006, 16 stations, covering approximately 280 acres of forested habitat, containing the historical nesting territory, were surveyed using taped playback (Figure 19). No responses were detected.

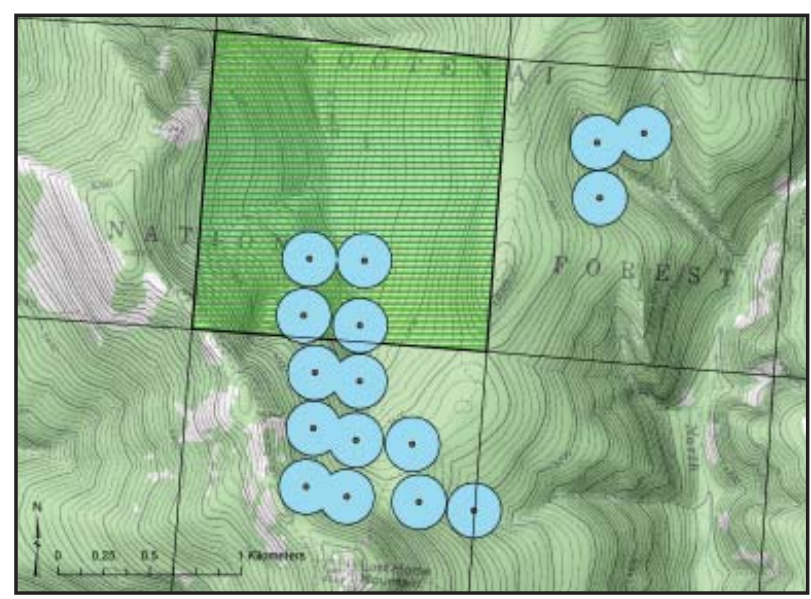

Figure 19. Location of call stations in Unnamed \#2 (Lost Horse Mtn.) historical territory.

\section{Historical Territories Determined}

Unnecessary to Survey

Sheppard - 30N 26W sec. 8

Wolf Creek - 29N 28W sec. 23

These two historical territories are currently owned by Plum Creek Timber Company in the region of the Libby Ranger District. After consultation with Plum Creek-Libby Office biologists and review of aerial photographs of these sections, it was determined surveys were unnecessary as the sections were recently completely harvested and contained no suitable nest sites.

\section{Wyoma $-30 \mathrm{~N}$ 26W sec. 16}

After consultation with Wildlife Biologists in the Libby Ranger District and review of aerial photographs, it was determined survey of this historical territory was unnecessary as this section has been heavily harvested and contains an unforested open landscape with no suitable nest sites.

\section{High-quality Potential Nesting Habitat Parcels}

The following areas were surveyed for Northern Goshawk presence in 2006 and 2007. Surveys were restricted to suitable forested habitat within the area. Four high-quality potential nesting habitat parcels and one reported potential nesting area were surveyed in the Three Rivers District. For map reference: Blue polygons - DEFF (designated effective old-growth); Red polygons - UEFF (undesignated effective old-growth; Orange polygons - DREP (designated replacement stand); and Green polygons - UREP (undesignated replacement stand).

\section{Three Rivers District}

Beetle Creek - 36N 33W sec. 2, 3, 10 and 11

On 28 June 2007, 18 stations, covering approximately 298 acres of forested habitat containing the historical nesting territory, were surveyed using taped playback (Figure 20). During the 10th call station within the area of the historical territory an investigation was made in response to taped playback by an adult Northern Goshawk at 11:06 am. This adult was observed flying into the 
call station area from the east and landing in a tree above the observers. The exact location of the call station was: (NAD 27) Zone 11: Easting - 584902 Northing - 5417559 (Locational Accuracy 20 meters) in the SW corner of the SW corner of T36NR33W sec.2. Gender was not possible to determine as this bird immediately flew off to the north. A detailed search of the vicinity, for the bird, a nest, and/or whitewash was conducted with additional abbreviated taped playback made to the east, north, and south of the call station. No nest was found and no subsequent visual observations were made. An adult goshawk responding to taped "kek-kek" calls during the breeding season indicates a possible nesting pair somewhere in the Beetle Creek/Pete Creek drainage. Further survey work in the vicinity may yield a new nest location.

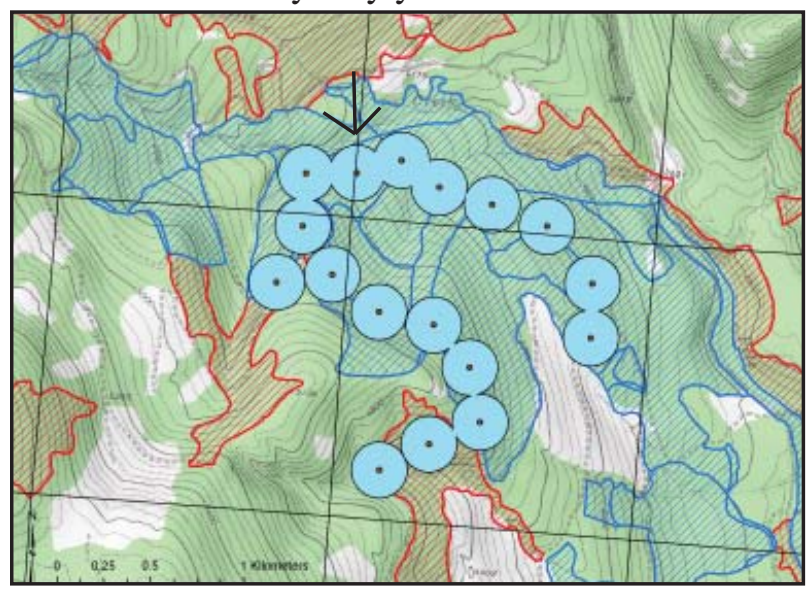

Figure 20. Location of call stations in Beetle Creek potential high-quality habitat parcel. Location of 2007 positive response at 10th station indicated by arrow.

Boyd Hill - 37N 31W sec. 13, 14, 23 and 24 On 26 June 2007, 9 stations, covering approximately 149 acres of forested habitat were surveyed using taped playback (Figure 21). This site was not originally chosen for survey. Three Rivers District Biologist Glen Gill had received a report of a possible Northern Goshawk pair calling in the area. While no goshawk responses were detected, a pair of Pileated Woodpeckers responded vocally to Northern Goshawk taped playback at 3 successive call stations.

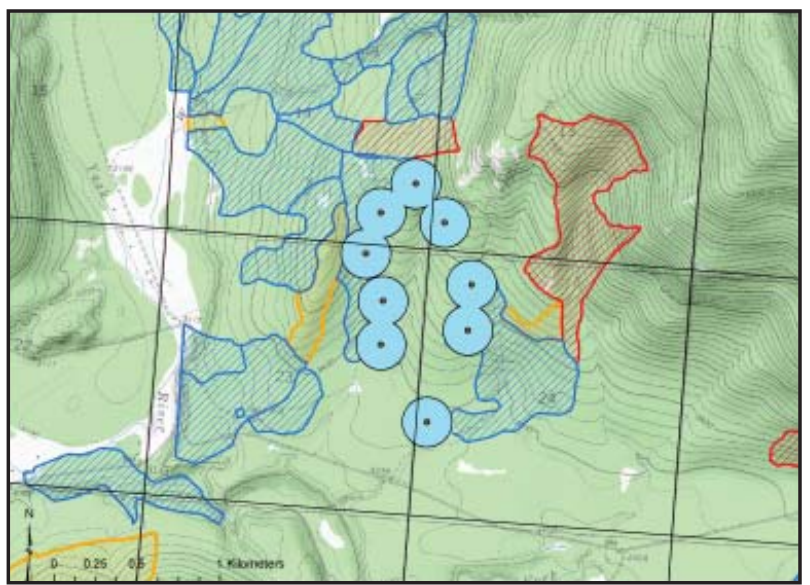

Figure 21. Location of call stations in Boyd Hill potential nesting area.

\section{Cougar Ridge - 34N 34W sec. 32, 33 and 33N 34W sec. 4}

On 26 and 29 June 2007, 25 stations, covering approximately 280 acres of forested habitat were surveyed using taped playback (Figure 22). The areas to the west and south were private land. No responses were detected.

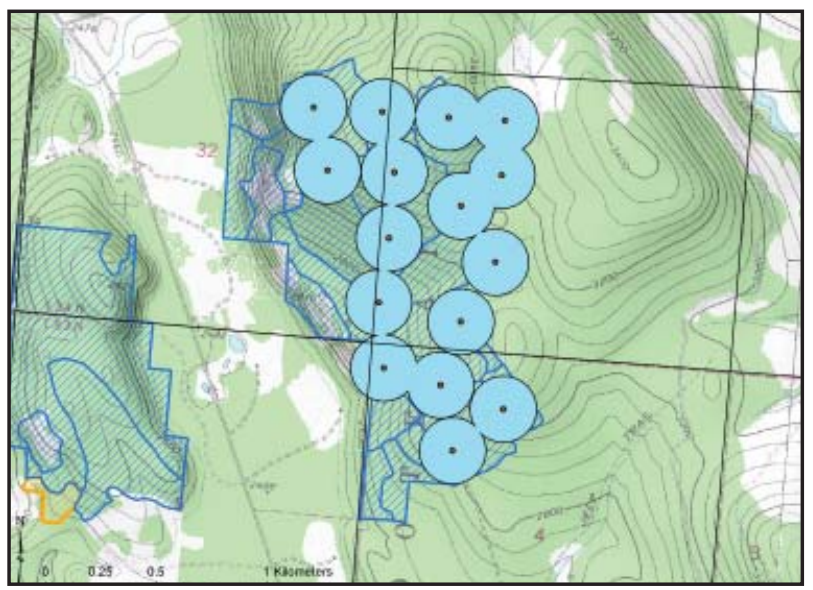

Figure 22. Location of call stations in Cougar Ridge potential high-quality habitat parcel. 


\section{Kookoo Creek - 37N 31W sec. 7, 8, 17, 18 and 20}

On 29 July 2007, 27 stations, covering approximately 473 acres of forested habitat were surveyed using taped playback (Figure 23). No responses were detected.

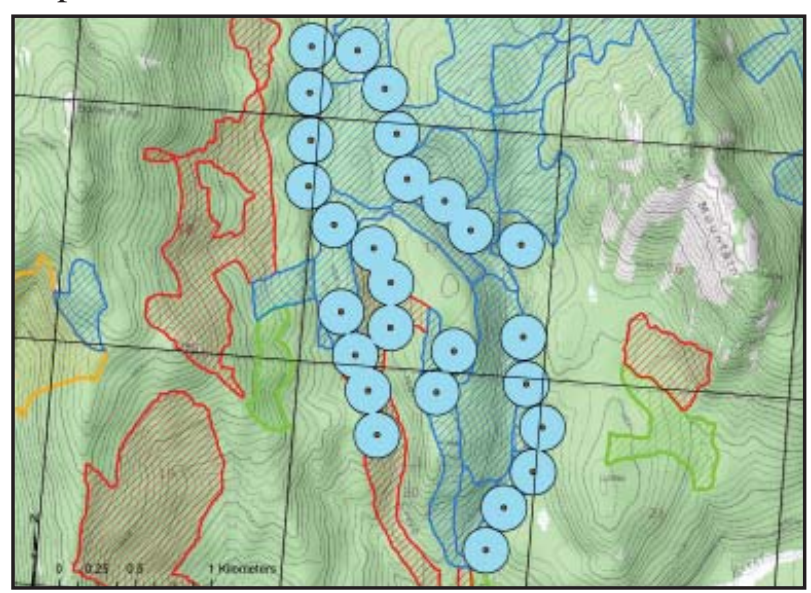

Figure 23. Location of call stations in Kookoo Creek potential high-quality habitat parcel.

\section{O’Brien Creek - 32N 33W sec. 1, 2, 3, 12, 13 and 14}

On 4 July 2006, 25 stations, covering approximately 438 acres of forested habitat were surveyed using taped playback (Figure 24). No responses were detected.

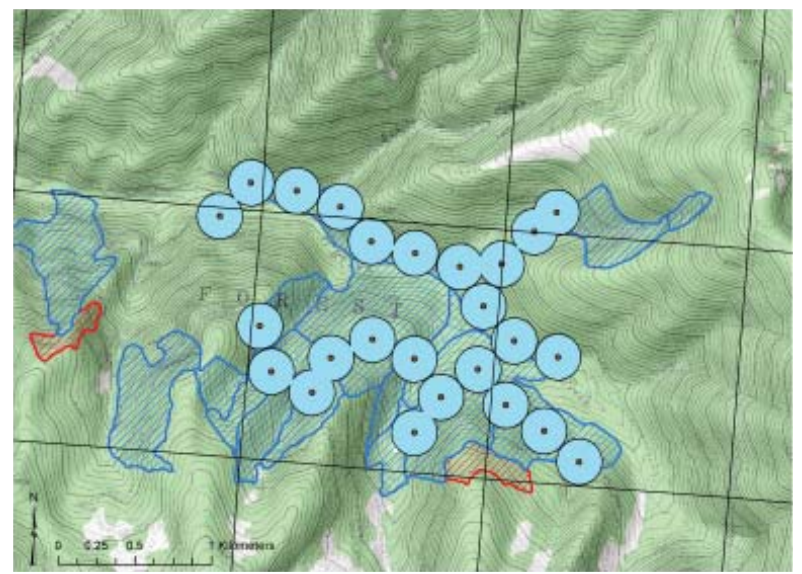

Figure 24. Location of call stations in O'Brien Creek potential high-quality habitat parcel.

\section{Old-growth Predictive Model}

The Montana Natural Heritage Program's Point Observation Database (POD) contains 180

Northern Goshawk observations within the boundaries of the Kootenai National Forest dating back to 1924. Fifty-four of these are considered breeding occurrences and, with the exception of the Bull River / Lake Creek region, are distributed across the entire Forest (Figure 25). Of these 54, only 29 occurrences had high spatial precision (locational uncertainty less than 500 meters). Because these 29 breeding observations only dated back to 1978, we felt it was worth comparing these locations with the Forest's old-growth predictive models since areas currently predicted as being old growth would have also have been old growth in 1978. Nineteen (66\%) of the 29 breeding observations are located less than 500 meters from one of the four old-growth stand types (DEFF, UEFF, DREP, UREP). Therefore, the old-growth predictive model may indeed be of use in selecting priority areas for future surveys. 


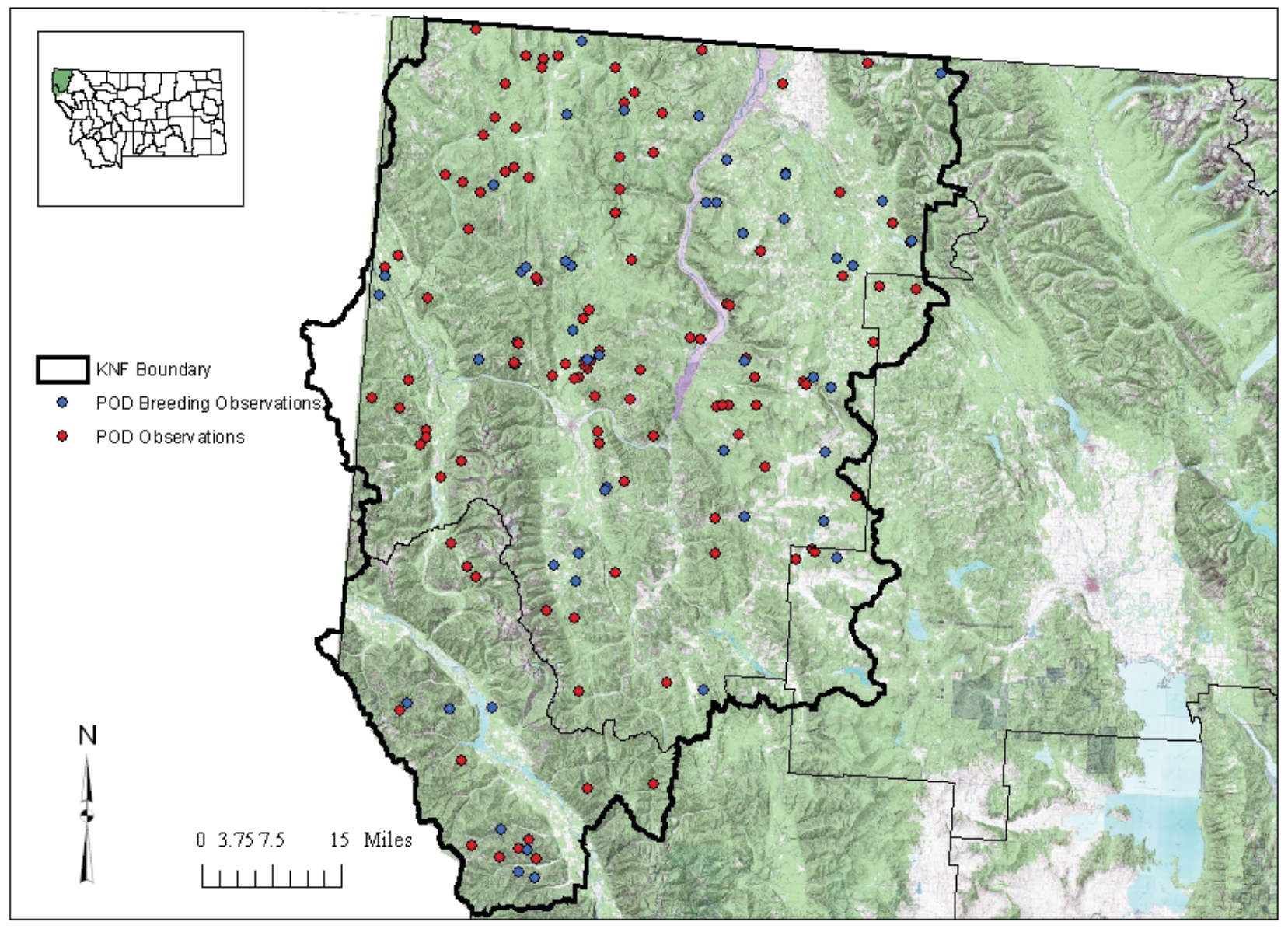

Figure 25. Breeding and non-breeding Northern Goshawk observations on the Kootenai Nional Forest 


\section{Suggestions FOR FUTURE}

Between 2005 and 2007, all known historical breeding territories for Northern Goshawks on the Kootenai National Forest were either surveyed or determined inappropriate for survey. Of the 17 historical territories actually surveyed, only one still maintained an active goshawk territory (Haines Gulch). Also, a positive response by an adult goshawk to taped playback at another historical territory (Purcell) likely indicates an active territory somewhere in the East Fork Pipe Creek drainage. Future surveys at these two specific areas to determine the territory and nest location is suggested.

The Kootenai National Forest defines a historical territory as one not surveyed in three or more years. Certainly, since these most recent surveys, a number of additional territories now fit this criteria and are in need of survey. I suggest any territory in the forest with no survey conducted in the past three years be surveyed for continued Northern Goshawk presence.

The surveys conducted on these historical areas were only a portion of the overall objectives for a multi-year project to document occurrence and habitat use of Northern Goshawks on the Kootenai
National Forest. The other portion involved conducting surveys of high-quality potential nesting habitat parcels as identified by predictive old-growth models. During 2006 and 2007, five such parcels were selected and surveyed resulting in one positive response of an adult goshawk (Beetle Creek). This approach for allocating survey effort resulted in a significantly greater rate of goshawk detection than the survey of historical nesting territories. This result suggests future surveys of predicted habitat may indeed yield more active goshawk territories. As there are still many more areas in the Forest satisfying the requirements of the predictive model, I suggest surveys of these areas be given the high priority in the future. I also suggest returning to the Beetle Creek/Pete Creek area in the hope of identifying the territory and nest location.

Finally, the USFS Northern Region conducted presence/absence surveys on the Kootenai National Forest in 2005 which resulted in two positive responses. However, nests were not located in these particular surveys efforts. I therefore suggest follow-up surveys be conducted in the vicinity of these two positive goshawk responses detected during those Region 1 surveys. 


\section{Literature Cited}

Beebe, F. L. 1974. Goshawk. Pp. 54-62 in Field studies of the Falconiformes of British Columbia. British Columbia Provincial Museum. Occasional Papers. Series No. 17.

Hayward, G. D. and R. E. Escano. 1989. Goshawk nest-site characteristics in western Montana and northern Idaho. Condor 91: 476-479.

Henny, C. J., R. A. Olson, and T. L. Fleming. 1985. Breeding chronology, molt, and measurements of accipiter hawks in northeastern Oregon. Journal of Field Ornithology. 56: 97-112.

Lenard, S., J. Carlson, J. Ellis, C. Jones, and C. Tilly. 2003. P.D. Skaar's Montana Bird Distribution, 6th Edition. Montana Audubon, Helena, Montana.

McGowan, J. D. 1975. Distribution, density and productivity of goshawks in interior Alaska. Federal Aid Wildlife Restoration Project Report. W-17-4, W17-5, W-17-6, Job 10.6A. Alaska Department of Fish and Game.
Montana Natural Heritage Program and Montana Fish Wildlife and Parks. 2006. Montana animal species of concern. Helena, MT: Montana Natural Heritage Program and Montana Department of Fish Wildlife and Parks. 17 p.

Reynolds, R. T. and H. M. Wight. 1978. Distribution, density, and productivity of accipiter hawks in northeastern Oregon. Wilson Bulletin. 90: 182-196.

Squires, J. R. and R. T. Reynolds. 1997. Northern Goshawk (Accipiter gentiles). In The Birds of North America, No. 298 (A. Poole and F. Gill, editors.). The Academy of Natural Sciences, Philadelphia, PA, and The American Ornithologists’ Union, Washington, D.C. 

Appendix A. Global/State Rank Definitions 



\section{Heritage Program Ranks}

The international network of Natural Heritage Programs employs a standardized ranking system to denote global (range-wide) and state status. Species are assigned numeric ranks ranging from 1 to 5 , reflecting the relative degree to which they are "at-risk". Rank definitions are given below. A number of factors are considered in assigning ranks — the number, size and distribution of known "occurrences" or populations, population trends (if known), habitat sensitivity, and threat. Factors in a species' life history that make it especially vulnerable are also considered (e.g., dependence on a specific pollinator).

Global Rank Definitions (NatureServe 2003)

G1 Critically imperiled because of extreme rarity and/or other factors making it highly vulnerable to extinction

G2 Imperiled because of rarity and/or other factors making it vulnerable to extinction

G3 Vulnerable because of rarity or restricted range and/or other factors, even though it may be abundant at some of its locations

G4 Apparently secure, though it may be quite rare in parts of its range, especially at the periphery

G5 Demonstrably secure, though it may be quite rare in parts of its range, especially at the periphery

T1-5 Infraspecific Taxon (trinomial) - The status of infraspecific taxa (subspecies or varieties) are indicated by a “T-rank” following the species’ global rank

\section{State Rank Definitions}

S1

At high risk because of extremely limited and potentially declining numbers, extent and/or habitat, making it highly vulnerable to extirpation in the state

S2 At risk because of very limited and potentially declining numbers, extent and/or habitat, making it vulnerable to extirpation in the state

S3 Potentially at risk because of limited and potentially declining numbers, extent and/or habitat, even though it may be abundant in some areas

S4 Uncommon but not rare (although it may be rare in parts of its range), and usually widespread. Apparently not vulnerable in most of its range, but possibly cause for long-term concern Common, widespread, and abundant (although it may be rare in parts of its range). Not vulnerable in most of its range

\section{Combination RanKs}

G\#G\# or S\#S\# Range Rank-A numeric range rank (e.g., G2G3) used to indicate uncertainty about the exact status of a taxon

\section{QUALIFIERS}

NR

Q

\section{Not ranked}

Questionable taxonomy that may reduce conservation priority-Distinctiveness of this entity as a taxon at the current level is questionable; resolution of this uncertainty may result in change from a species to a subspecies or hybrid, or inclusion of this taxon in another taxon, with the resulting taxon having a lower-priority (numerically higher) conservation status rank 
X

H

U

HYB

?

C

A

Z

P

R

SYN

*

B

$\mathrm{N}$

Presumed Extinct-Species believed to be extinct throughout its range. Not located despite intensive searches of historical sites and other appropriate habitat, and virtually no likelihood that it will be rediscovered

Possibly Extinct - Species known from only historical occurrences, but may never-theless still be extant; further searching needed

Unrankable - Species currently unrankable due to lack of information or due to substantially conflicting information about status or trends

Hybrid —Entity not ranked because it represents an interspecific hybrid and not a species

Inexact Numeric Rank-Denotes inexact numeric rank

Captive or Cultivated Only_-Species at present is extant only in captivity or cultivation, or as a reintroduced population not yet established

Accidental-Species is accidental or casual in Montana, in other words, infrequent and outside usual range. Includes species (usually birds or butterflies) recorded once or only a few times at a location. A few of these species may have bred on the one or two occasions they were recorded

Zero Occurrences-Species is present but lacking practical conservation concern in Montana because there are no definable occurrences, although the taxon is native and appears regularly in Montana

Potential-Potential that species occurs in Montana but no extant or historic occurrences are accepted

Reported-Species reported in Montana but without a basis for either accepting or rejecting the report, or the report not yet reviewed locally. Some of these are very recent discoveries for which the program has not yet received first-hand information; others are old, obscure reports

Synonym - Species reported as occurring in Montana, but the Montana Natural Heritage Program does not recognize the taxon; therefore the species is not assigned a rank

A rank has been assigned and is under review. Contact the Montana Natural Heritage Program for assigned rank

Breeding-Rank refers to the breeding population of the species in Montana

Nonbreeding — Rank refers to the non-breeding population of the species in Montana

Appendix A - 2 